\title{
Laterality as a Predictor of Coping Strategies in Dogs Entering a Rescue Shelter
}

\author{
Shanis Barnard * (D), Deborah L. Wells and Peter G. Hepper \\ Animal Behaviour Centre, School of Psychology, Queen's University Belfast, Belfast BT7 1NN, UK; \\ d.wells@qub.ac.uk (D.L.W.); p.hepper@qub.ac.uk (P.G.H.) \\ * Correspondence: shanis.barnard@gmail.com
}

Received: 14 September 2018; Accepted: 19 October 2018; Published: 23 October 2018

\begin{abstract}
It has been reported that during the first few days following entry to a kennel environment, shelter dogs may suffer poor welfare. Previous work suggests that motor bias (the preferred use of one limb over the other) can potentially be used as an indicator of emotional reactivity and welfare risk. In this study, we investigate whether paw preference could be used as a predictive indicator of stress coping (measured using cortisol levels and behavioural observation) in a sample of 41 dogs entering a rescue shelter. Cortisol levels and behavioural observations were collected for one week after admission. We scored the dogs' paw preference during a food-retrieval task. Our results showed that increasing left-pawedness was associated with a higher expression of stress-related behaviours such as frequent change of state, vocalisations and lower body posture. These results are in keeping with previous findings showing that left-limb biased animals are more vulnerable to stress. Paw preference testing may be a useful tool for detecting different coping strategies in dogs entering a kennel environment and identifying target individuals at risk of reduced welfare.
\end{abstract}

Keywords: dog; laterality; paw preference; shelter; welfare

\section{Introduction}

Entering a rescue shelter can be a very stressful experience for dogs; they are separated from any social attachment figures, they are exposed to a novel environment (i.e., unfamiliar noise, smells, disruption of familiar routine) and to daily interactions with unfamiliar people and conspecifics [1-3]. Previous studies show how this transition can generate a state of fear, anxiety, and frustration $[4,5]$. Social and spatial restriction following confinement can be a cause of both acute and chronic stress [6-8]. Physiological studies have confirmed that kennelling is perceived by dogs as a psychogenic stressor, with animals displaying peaks in cortisol levels in the first few days after arrival [3,5,9]. Individual dogs, however, may have different coping abilities or stress resilience. Previous research has highlighted two main coping styles in individuals that are environmentally challenged: proactive and reactive [10]. Proactive coping styles may be more typical of 'bold' personality types and are defined by active attempts to counter the stressful stimuli and by low Hypothalamic-Pituitary-Adrenal (HPA)-axis reactivity. Reactive, or passive, coping may be more typical of 'shy' personality types, and involves higher activation of the HPA-axis system, immobility, and low levels of aggression [11,12]. Hiby and colleagues [13] found that dogs showing or not showing physiological adaptation to kennelling had different behavioural styles, that is, dogs with lower HPA-axis activation spent more of their time walking or trotting compared to dogs with high cortisol levels. Effective interventions to minimise signs of poor welfare should be based on the evaluation of dogs' individual ability to cope and adapt to confinement in kennels. Behavioural indicators offer excellent validated measures of welfare as they represent the output of a range of sensory and cognitive experiences and decision-making processes, reflecting the expression of the animal's underlying emotional and physiological state [14]. 
Unfortunately, behavioural analysis, live or from a video, has several limitations and disadvantages, including being very time consuming and requiring a large amount of labour, thereby limiting the amount of information that can be collected.

Recently, when evaluating the impact of the environment on confined animals, animal welfare scientists have focused their attention on the expression of positive emotions and on the link between emotional stress and cognitive processes [15-18]. The identification of reliable and practical cognitive indicators of emotional distress would allow us to target interventions aimed at improving dogs' quality of life.

Laterality has been used as a measure of emotionality, stress reaction, and temperament in different species [18-23]. Emotional informations are processed differently by the brain hemispheres according to their valence. It has been suggested that withdrawal-related emotions are processed and controlled primarily by the right hemisphere, while positive, approach-related emotions are controlled mainly by the left hemisphere $[24,25]$. However, the overall expression of intense emotions, independent of their valence, has been associated, by other scholars, to a right hemispheric dominance [26,27]. Behavioural laterality may reflect this divergent hemispheric processing. Higher emotional indices have been associated with right hemisphere activation in horses [28]. Lateralisation has been reported to be linked with the intensity of behavioural reactions in novel situations [23] and to boldness in exploring novel objects and environments [29,30]. Consistent individual behavioural differences in, for example, limb preference for simple reaching, may be linked to a dominant control of the contralateral brain hemisphere. This allows the use of behaviour as an indicator of brain laterality [20]. Right-handed marmosets (left hemispheric dominance), for example, were found to be more bold, readily approaching and exploring for longer a novel object in an unfamiliar environment compared to left-handed marmosets (right hemispheric dominance) [29]. A study by Batt and colleagues [31] found that a greater strength and directionality of laterality were linked with more confident and relaxed behaviour in dogs that were exposed to novel stimuli and unfamiliar environments. Thus, laterality appears to be a potential novel indicator of coping abilities and vulnerability to stress for domestic dogs entering a kennel environment.

Laterality in dogs has been largely studied in the form of paw preference [32-34]. In this study, we assessed, for the first time, the relationship between canine laterality, as determined by the commonly used Kong ball test $[23,33,35,36]$, and behavioural and physiological measures of stress in dogs admitted to a rescue shelter. The aim was to determine whether laterality could be used as a potential predictor of welfare risk in kennelled dogs.

\section{Methods}

\subsection{Animals}

Data collection was performed at the Dogs Trust Rehoming Centre in Ballymena, Co. Antrim, UK, over a period of 9 months. All dogs entering the shelter during this period were enrolled in the study; exceptions were made if the dog was pregnant, seriously ill or injured, impossible to handle or walk on the lead due to excessive fear or aggression. A total of 41 dogs were assessed, 22 males (54.5\% neutered) and 19 females (58.0\% spayed), including a number of different purebreds and crossbreeds. The minimum age for a subject to be enrolled was 12 months; the oldest dog in our sample was 9 years (median $=3$ years; mean \pm SD $3.7 \pm 2.5$ years) (Table 1$)$. 
Table 1. Demographics of dogs included in the study.

\begin{tabular}{|c|c|c|c|c|c|}
\hline Dog ID & Name & Breed & Sex & Age (Years) & Castration \\
\hline 1 & Roxy & TerrierX & $\mathrm{F}$ & 5 & yes \\
\hline 2 & Ginger & TerrierX & $\mathrm{F}$ & 5 & yes \\
\hline 3 & Albert & LhasaApso & $\mathrm{M}$ & 4.5 & yes \\
\hline 4 & Jojoe & BeardCollie & $\mathrm{M}$ & 5 & yes \\
\hline 5 & Dandy & Poodle & $\mathrm{M}$ & 6 & yes \\
\hline 6 & Curly & Poodle & $\mathrm{M}$ & 6 & yes \\
\hline 7 & Lucy & $\mathrm{Lab}$ & $\mathrm{F}$ & 1.5 & yes \\
\hline 8 & Bailey & KingCharles & $\mathrm{M}$ & 5 & no \\
\hline 9 & Ermet & JackRuss & $\mathrm{M}$ & 1.4 & yes \\
\hline 10 & Leo & JackRussX & M & 1 & no \\
\hline 11 & Tiny & MinShetland & $\mathrm{F}$ & 8 & no \\
\hline 12 & Orsha & CockerSp & F & 2 & yes \\
\hline 13 & $\operatorname{Rex}$ & Springer & $\mathrm{M}$ & 1 & no \\
\hline 14 & Socks & RughCollie & $\mathrm{M}$ & 1.5 & yes \\
\hline 15 & Roy & Collie & $\mathrm{M}$ & 3 & yes \\
\hline 16 & Dappy & Pugalier & $\mathrm{M}$ & 1.5 & no \\
\hline 17 & Prince & $\mathrm{Lab}$ & $\mathrm{M}$ & 4 & no \\
\hline 18 & Darcy & Husky & $\mathrm{F}$ & 3 & yes \\
\hline 19 & Svaras & $\mathrm{Lab}$ & M & 2.5 & no \\
\hline 20 & Roxy & LabX & $\mathrm{F}$ & 3 & yes \\
\hline 21 & Milly & CarinTerr & $\mathrm{F}$ & 9 & yes \\
\hline 22 & Willy & CarinTerr & $\mathrm{M}$ & 9 & yes \\
\hline 23 & Biddy & FoxTerr & $\mathrm{F}$ & 5 & yes \\
\hline 24 & Maggie & Jug & $\mathrm{F}$ & 1.5 & no \\
\hline 25 & Missy & IrishTerr & $\mathrm{F}$ & 9 & yes \\
\hline 26 & Maya & LabPitX & $\mathrm{F}$ & 4 & no \\
\hline 27 & Harley & Dobie & $\mathrm{M}$ & 1 & no \\
\hline 28 & Dax & Dasch & $\mathrm{M}$ & 2 & no \\
\hline 29 & Miles & Dasch & M & 2.5 & yes \\
\hline 30 & $\operatorname{Max}$ & IrishWater & $\mathrm{M}$ & 1.5 & no \\
\hline 31 & Charlie & Collie & $\mathrm{M}$ & 1 & yes \\
\hline 32 & Tess & PatterdaleX & F & 1 & yes \\
\hline 33 & Zoe & JackRuss & $\mathrm{F}$ & 2 & no \\
\hline 34 & Tia & Shihtzu & $\mathrm{F}$ & 8 & no \\
\hline 35 & Gizmo & Maltese & $\mathrm{M}$ & 6 & no \\
\hline 36 & Lily & Shorky & $\mathrm{F}$ & 2.5 & no \\
\hline 37 & Benson & CollieX & $\mathrm{M}$ & 1.5 & yes \\
\hline 38 & Honey & Yorkie & $\mathrm{F}$ & 7 & no \\
\hline 39 & Coco & TerrierX & $\mathrm{F}$ & 5 & no \\
\hline 40 & Enzo & JackRuss & $\mathrm{M}$ & 2.5 & yes \\
\hline 41 & Aria & JackRuss & $\mathrm{F}$ & 2 & yes \\
\hline
\end{tabular}

A portion of dogs (14.6\%, unknown history), were rescued from the municipal pound or other shelters and the remainder were surrendered to the Dogs Trust by their owners for a variety of reasons. Main reasons included family health issues (e.g., allergies or illness of a family member), work commitments (i.e., not being able to take care of the dog anymore), owner's death, or moving home as most common (Table 2). 
Table 2. Reasons provided by the owners when surrendering their dogs to the rescue centre.

\begin{tabular}{ccc}
\hline Reason for Surrender & Cases & $\%$ \\
\hline Family health & 9 & 22.0 \\
Work commitments & 7 & 17.1 \\
Pound/other shelters & 6 & 14.6 \\
Owner's death & 5 & 12.2 \\
Moving home & 4 & 9.8 \\
Behavioural problems & 2 & 4.9 \\
Handover/rescued & 2 & 4.9 \\
Problem with other household dogs & 2 & 4.9 \\
Too many dogs in household & 2 & 4.9 \\
From breeding stock & 1 & 2.4 \\
New born baby & 1 & 2.4 \\
Total & 41 & 100 \\
\hline
\end{tabular}

\subsection{Procedure}

On the day of admission to the shelter (Day 0), dogs were enrolled and general information collected from shelter records (sex, age, provenience, date of entrance, etc.). Data collection started on the following morning (Day 1) for one week, with sampling occurring on days 2, 3, 5 and 7. On each of the sampling days, both urine samples and behavioural recordings were collected following the protocols described below. Paw preference was assessed once on Day 3, see later (Section 2.2.3). The day of paw preference assessment was decided during pilot testing: it was noticed that dogs were not interested in the toy during their first two days in the kennels, whereas on day three most dogs would actively interact with, and retrieve food from, the ball.

\subsubsection{Urine Cortisol/Creatinine Ratio}

Between 08:00 $\mathrm{h}$ and 10:00 h of sampling days (1, 2, 3, 5, and 7), dogs were leashed and walked outdoors; a mid-stream sample of naturally voided urine was collected using urine sampling kits (Rocket ${ }^{\circledR}$ URIPET ${ }^{\mathrm{TM}}$, Washington, WA, USA). Urine tubes were labelled and stored at $-30{ }^{\circ} \mathrm{C}$ for up to 3 months. Samples were shipped in batches to IDEXX laboratories (West Yorkshire, UK) and tested for cortisol/creatinine (C/C) ratio. Cortisol was extracted with chemiluminescent competitive immunoassay using the Siemens Immulite 2000, whereas creatinine with Jaffe (alkaline picrate) reaction using the Beckman AU 5800 analyser.

\subsubsection{Behavioural Observations}

Behavioural observations started after urine sampling (Days 1, 2, 3, 5, and 7). A digital camera on a tripod was positioned in front of the kennel and recorded the behaviour of each dog over three sessions of $35 \mathrm{~min}$ (30 central minutes extracted for analysis). Members of staff prioritised cleaning the kennels and feeding the dogs that were going to be recorded on that day. This allowed no interruptions during recording. Routine activities, however, continued as normal in the adjacent kennels. Observational sessions were distributed as follows: Session 1 (OB1) between 09:00 $\mathrm{h}$ and 10:00 h, during morning activities. Session 2 (OB2) between 11:00 $\mathrm{h}$ and 12:00 h during staff tea break; Session 3 (OB3) between 13:00 $\mathrm{h}$ and 15:00 during visiting hours (the Centre opened to the public between 12:00 and 16:00 h). The sessions were planned this way to allow for an overview of the range of behaviours that dogs performed across a typical day.

\subsubsection{Paw Preference Assessment}

Dogs' paw preferences were assessed on Day 3 using the 'Kong ball test', one of the most commonly used measures of canine motor bias [33,35,36]. Following previously published protocols, each dog was allowed to sniff a Kong Ball ${ }^{\mathrm{TM}}$ (KONG Company, Golden, CO, USA; a hollow conical-shaped toy) filled with dog food. Then the Kong was placed inside the kennel on the floor 
centrally in front of the animal. The paw used (left, right) by the dog to hold/stabilise the toy was recorded using a smartphone app purposely developed for this study. The test continued until 100 paw uses (left or right) had been made. The use of both paws was recorded but not counted towards this total. The use of the app had several advantages, including not having to interrupt eye contact with the subject to write down the scores, recording would automatically stop when the 100 paw-use target was reached, main statistics for the dog appeared immediately on the screen, and raw data were readily available for download in Microsoft Excel format. A single paw use was recorded regardless of how long the paw stayed on the ball. The animal was required to remove its paw completely from the ball for paw use to be scored as a separate response. Dogs were tested for approximately $30 \mathrm{~min}$ (the average length of time taken to collect 100 data points).

\subsection{Analysis}

All analyses were carried out using IBM SPSS Statistics 21.0 (IBM, Armonk, NY, USA).

\subsubsection{Paw Preference Assessment}

Individual laterality scores were calculated using a binomial test and converted to a $z$-score using the formula $z=(\mathrm{L}-0.5 \mathrm{~N}) / \sqrt{ }(0.25 \mathrm{~N}), \mathrm{L}$ being the number of left paw uses and $\mathrm{N}$ the total of left and right paw uses. A $z$-score $\geq 1.96$ indicates a left paw bias, a $z$-score $\leq-1.96$ indicates a right paw bias; a value between these two scores indicates no lateral bias (ambilateral) [33,36]. A chi-squared test was used to calculate departures from random distribution of left-, right- and ambilateral paw preference groups. Paw-preferent (either to the left or right) vs. ambilateral, and right- vs. left-paw preferent animals were compared using binomial tests to assess any significant group difference. Chi-squared tests were also used to assess whether the pawedness classification was associated with the dogs' sex (male, female) or castration status (neutered, intact).

A directional laterality index (LI) was calculated to quantify each dog's paw preference on a continuum from strongly left-paw preferent $(+1)$ to strongly right-paw-preferent $(-1)$. The LI score was calculated as $(L-R) /(L+R)$, where $R$ represents the number of right paws and $L$ the number of left paws used [30]. A score of 0 indicates no bias, a score of \pm 1 indicates that the subject used the same paw throughout the trial. In addition to the directional bias of lateral behaviour (i.e., left or right bias), the strength of laterality has also been used as a proxy measure of hemispheric brain activity. Strongly lateralised animals show a greater activity of one hemisphere (irrespective of the side), while weakly lateralised animals do not show a significant dominance of one hemisphere over the other (i.e., ambilateral) [25]. The absolute value of LI (LI_ABS) gives a measure of the strength of laterality, irrespective of the direction of paw use. A Shapiro-Wilk normality test was used to assess the distribution of LI and LI_ABS values to identify any population bias. Any effect of sex or castration status on the direction and strength of laterality was calculated using a Mann-Whitney-U test for independent samples.

\subsubsection{Behavioural Analysis}

A total of $307.5 \mathrm{~h}$ of footage was analysed. Videos were scored using the behavioural recording software The Observer XT13 (Noldus, The Netherlands). Due to time and resource constraints we used an instantaneous sampling method. However, given that some behaviours (e.g., barking) might have been lost or underestimated using this approach, we also scored a subset of videos using continuous sampling (Table 3). Instantaneous sampling was used every $60 \mathrm{~s}$ : the observer recorded the behaviour expressed by the focal animal at a given instant and scoring was performed for all the video footage (i.e., 90 data points per observational day, 450 data points for the 5 days). Continuous sampling was performed during the first 15 min of recoding of session OB1 on each of the 5 sampling days. 
Table 3. Behavioural variables recorded during the behavioural observations either using instantaneous (i) or continuous (c) sampling techniques. During the latter, behaviours could be scored as either duration (d) or frequency (f).

\begin{tabular}{|c|c|c|}
\hline Label & Behaviour Description & Sampling Method \\
\hline \multirow{4}{*}{ Inactive behaviours } & Stand: the dog is still, standing on fours & (i) \\
\hline & Sit: the dog is sitting on hind legs & (i) \\
\hline & $\begin{array}{l}\text { Lie down: the dog is in a recumbent position with the } \\
\text { head up (vigilant) }\end{array}$ & (i) \\
\hline & $\begin{array}{l}\text { Rest/sleep: the dog is lying on the floor or curled up in } \\
\text { the bed with the head also on the ground, likely eyes are } \\
\text { closed although not always visible. }\end{array}$ & (i) \\
\hline \multirow{3}{*}{ Posture } & $\begin{array}{l}\text { High: the tail and/or the head are held high and the ears } \\
\text { are forward and/or the animal is standing in an elevated } \\
\text { posture compared to the neutral breed posture }\end{array}$ & (i) \\
\hline & $\begin{array}{l}\text { Neutral: breed specific posture in neutral conditions } \\
\text { (mouth, ears and tail are relaxed) }\end{array}$ & (i) \\
\hline & $\begin{array}{l}\text { Low: lowered positions of the tail (or tail curled forward } \\
\text { between the hind legs) and/or bent legs and/or } \\
\text { backward positioning of the ears compared to neutral } \\
\text { conditions }\end{array}$ & (i) \\
\hline \multirow{2}{*}{ Moving } & $\begin{array}{l}\text { Walking: the dog is moving step by step with a normal } \\
\text { pace (compared to its breed and size) }\end{array}$ & (i) \\
\hline & $\begin{array}{l}\text { Trotting: the dog is moving with a faster gait compared } \\
\text { to walking }\end{array}$ & (i) \\
\hline Change of state & $\begin{array}{l}\text { Scored each time the dog changed from one inactive } \\
\text { behaviour to another (e.g., sit to lie down) or from an } \\
\text { inactive behaviour to an active one (e.g., stand to walk) }\end{array}$ & (c) (f) \\
\hline & Barking: short staccato vocalization & (c) (f) \\
\hline Vocalisations & Howling/whining: the dog is howling or whining & (c) $(\mathrm{f})$ \\
\hline & Growling: the dog is growling & (c) (f) \\
\hline \multirow[t]{2}{*}{ Socialising (with pen mate) } & $\begin{array}{l}\text { Positive: affiliative behaviour, playing behaviour and/or } \\
\text { greeting behaviour }\end{array}$ & (c) (d) \\
\hline & Negative: threatening behaviour and/or aggression & (c) (d) \\
\hline Repetitive behaviour & $\begin{array}{l}\text { Presence of stereotypical behaviour (e.g., pacing, circling, } \\
\text { repetitive jumping on the fence, tail chasing or any other } \\
\text { behaviour repeated in the same way for several times } \\
\text { without any seeming function) throughout the test phase }\end{array}$ & (c) (d) \\
\hline Stress-related behaviour & $\begin{array}{l}\text { Behaviours that are potentially related to stressful } \\
\text { conditions, in particular licking lips, panting, drinking, } \\
\text { grooming/scratching, body shaking, digging at walls, } \\
\text { doors or floor, paw lifting, yawning and startling }\end{array}$ & (c) $(\mathrm{f})$ \\
\hline Play & $\begin{array}{l}\text { Individual playing behaviour (e.g., grabbing or holding } \\
\text { an object in the mouth and head-shaking, play bow) }\end{array}$ & (c) (d) \\
\hline \multirow{3}{*}{ Other } & Scratching: Dog is scratching the floor or the walls & (c) (d) \\
\hline & $\begin{array}{l}\text { Rear wall: Dog rears up against the window or side } \\
\text { walls, including bouncing in an excited manner }\end{array}$ & (c) (d) \\
\hline & Drinking: Dog is drinking water from the bowl & (i) \\
\hline
\end{tabular}

\subsubsection{Predictive Factors Affecting Behavioural Variations}

To investigate if any variation in behaviour could be associated with the observation time, days from shelter entrance, sex, castration status, C/C ratio or laterality (either direction or strength), we performed Linear Mixed Model (LMM) analysis with each behaviour as the dependent variable and sex, castration status, observation times, day, C/C, LI and LI_ABS as predictive factors and dog identity as random. 


\subsubsection{Laterality as a Predictive Factor of C/C Level Variation}

To investigate if any variation in cortisol levels throughout the observation time could be predicted by laterality (either direction or strength), we performed LMM with C/C ratio as the dependent variable and day of observation as the repeated measure, LI and LI_ABS as predictive variables, and dog identity as a random factor.

\section{Results}

\subsection{Paw Preference Assessment}

When calculating lateralisation at the individual level, 8 (19.5\%) dogs mainly used their left paw to hold the Kong, 18 (43.9\%) mainly used their right paw and 14 (34.1\%) used both paws equally. Binomial tests showed no significant difference between the distribution of lateralised and ambilateral $\operatorname{dogs}(p=0.81)$ or between the number of left and right pawed dogs $(p=0.80)$. Paw preference was not successfully recorded for one $\operatorname{dog}(2.5 \%)$.

The distribution of the three pawedness classification groups did not differ significantly from that expected by chance, that is, no population level effect $\left(\chi^{2} 2,40=3.80, p=0.15\right)$.

No significant association emerged between dogs' paw preference classification and sex or castration status $\left(\chi^{2}{ }_{2,40}=1.48, p=0.48 ; \chi^{2}{ }_{2,40}=3.98, p=0.14\right.$ respectively).

No population bias was recorded when exploring either the direction of laterality (using LI scores) or the absolute strength of laterality ( $\mathrm{W}=0.95, p=0.59 ; \mathrm{W}=0.96 ; p=0.18$ respectively).

Direction and strength of laterality were not significantly affected by the sex of the dogs or their castration status (Sex: $Z_{\mathrm{LI}}=-0.03, p=0.98 ; \mathrm{Z}_{|\mathrm{LI}|}=-1.53, p=0.13$; Neutering: $\mathrm{Z}_{\mathrm{LI}}=-0.52, p=0.60$; $\left.\mathrm{Z}_{|\mathrm{LI}|}=-1.19, p=0.23\right)$.

\subsection{Behavioural Data Management}

Given that the different sampling methods (instantaneous and continuous) were performed for different lengths of time, analyses were kept separate using two different datasets. From an initial inspection, a few behaviours were performed only rarely or by a small number of animals. Only behaviours with a median $>0$ were included in the analysis. Behaviours excluded were: play, socialising, repetitive behaviours, stress-related behaviours, and all behaviours under 'other'. Walking and trotting were analysed as one variable termed 'moving', while barking, howling/whining, and growling were analysed as one variable termed 'vocalisations'.

\subsection{Predictive Factors Affecting Behavioural Variations}

The dogs' behaviour did not vary greatly over their first week in the rescue shelter (Table 4), with the exception of 'posture', with dogs showing an increase in higher posture over time (D1 = $2.7 \pm$ $5.4 ; \mathrm{D} 3=4.2 \pm 6.9 ; \mathrm{D} 7=5.6 \pm 6.9$ ). The time of observation had a significant effect on the expression of behaviours including standing, resting/sleeping, and maintaining a low posture (Table 4). Descriptive analysis showed that dogs spent less time standing during the second bout of observation $t(\mathrm{OB} 2)$ (i.e., staff break, $8.1 \pm 6.9$ ) compared to OB1 (i.e., cleaning, $12.3 \pm 8.1$ ) and OB3 (i.e., visiting hours, $12.0 \pm 7.8)$. On the contrary, dogs spent more time resting/sleeping during the second observation bout (OB2) $(7.4 \pm 8.4)$ compared to OB1 $(4.4 \pm 7.2)$ and OB3 (4.2 \pm 6.1$)$. Finally, dogs were likely to show less low posture during the second observation bout (OB2) $(4.1 \pm 5.6)$ compared to OB1 $(6.4 \pm 7.4)$ and $\mathrm{OB} 3(6.4 \pm 7.4)$. These outcomes are rather intuitive as dogs were undisturbed, thus mainly resting during OB2 and scored as having neutral posture. 
Table 4. Linear Mixed Models output. Dependent variables (i.e., behaviours) on the row and predictive variables on the columns. Cells show F-values and significance levels.

\begin{tabular}{ccccccccc}
\hline Variable & df & Day & OB & N/S & Sex & C/C & LI & ABS_LI \\
\hline Stand & 419 & 0.62 & $16.9^{* * *}$ & $17.5^{* * *}$ & $4.5^{*}$ & $15.6^{* * *}$ & 0.34 & $35.3^{* * *}$ \\
Rest/Sleep & 419 & 0.98 & $7.6^{* *}$ & 1.0 & 0.12 & 0.57 & $12.5^{* * *}$ & $27.0^{* * *}$ \\
Lie down & 419 & 1.4 & $1.8^{* * *}$ & $34.3^{* * *}$ & 4.4 & $28.9^{* * *}$ & $8.0^{* *}$ & $6.5^{*}$ \\
Sit & 419 & 1.5 & $0.7^{* * *}$ & 0.05 & 0.002 & $8.7^{* *}$ & $53.7^{* * *}$ & $0.6^{* *}$ \\
Moving & 419 & 1.3 & 1.4 & $7.6^{* *}$ & 0.6 & $10.3^{* *}$ & $11.7^{* *}$ & $1.7^{* *}$ \\
Low posture & 419 & 2.05 & $5.2^{* *}$ & $6.5^{*}$ & 0.005 & $1.6^{* *}$ & $7.2^{* *}$ & $24.1^{* * *}$ \\
High posture & 419 & $2.6^{*}$ & 2.5 & 3.9 & 0.03 & $25.6^{* * *}$ & 3.01 & $7.8^{* *}$ \\
Change posture & 133 & 0.5 & NA & 0.7 & 0.04 & 1.6 & $10.7^{* *}$ & $0.4^{* *}$ \\
Vocalisations & 133 & 0.6 & NA & 1.3 & 3.8 & 0.9 & $14.4^{* * *}$ & $19.4^{* * *}$ \\
\hline
\end{tabular}

$\mathrm{df}=$ degrees of freedom; $\mathrm{OB}=$ observation time; $\mathrm{N} / \mathrm{S}=$ neuter/spay; $\mathrm{C} / \mathrm{C}=$ cortisol/creatinine ratio; $\mathrm{LI}=$ laterality index; ABS_LI = strength of laterality; ${ }^{*} p<0.05 ;{ }^{* *} p<0.001 ;{ }^{* * *} p<0.0001$.

Sex and castration status had an effect on the expression of a few behaviours (Table 4); descriptive analysis highlighted that male dogs spent slightly more time standing $(11.1 \pm 7.4)$ than female dogs $(10.3 \pm 8.3)$. Entire dogs spent more time standing (11.4 \pm 8.2$)$, less time moving $(1.5 \pm 1.8)$, and less time lying $(3.4 \pm 4.8)$ than neutered/spayed dogs (10.2 $\pm 7.6 ; 2.6 \pm 3.4 ; 5.2 \pm 6.2$ respectively).

Variations in cortisol levels were associated with variation in behaviour expression (Table 4). Dogs with increasingly higher cortisol levels were more likely to spend time inactive (sitting and lying down) but less time moving, standing, and showing a high posture (Table 4).

LMM analysis highlighted a significant effect of both LI and ABS_LI on a number of behaviours (Table 4). Increasing left pawedness was associated with more frequent change of state, more time spent vocalising (Figure 1a), sitting (Figure 1b), and showing a lower posture (Figure 1c). By contrast, dogs with increasingly strong right-paw bias were likely to spend more time resting/sleeping, lying down (Figure 1d) and moving.

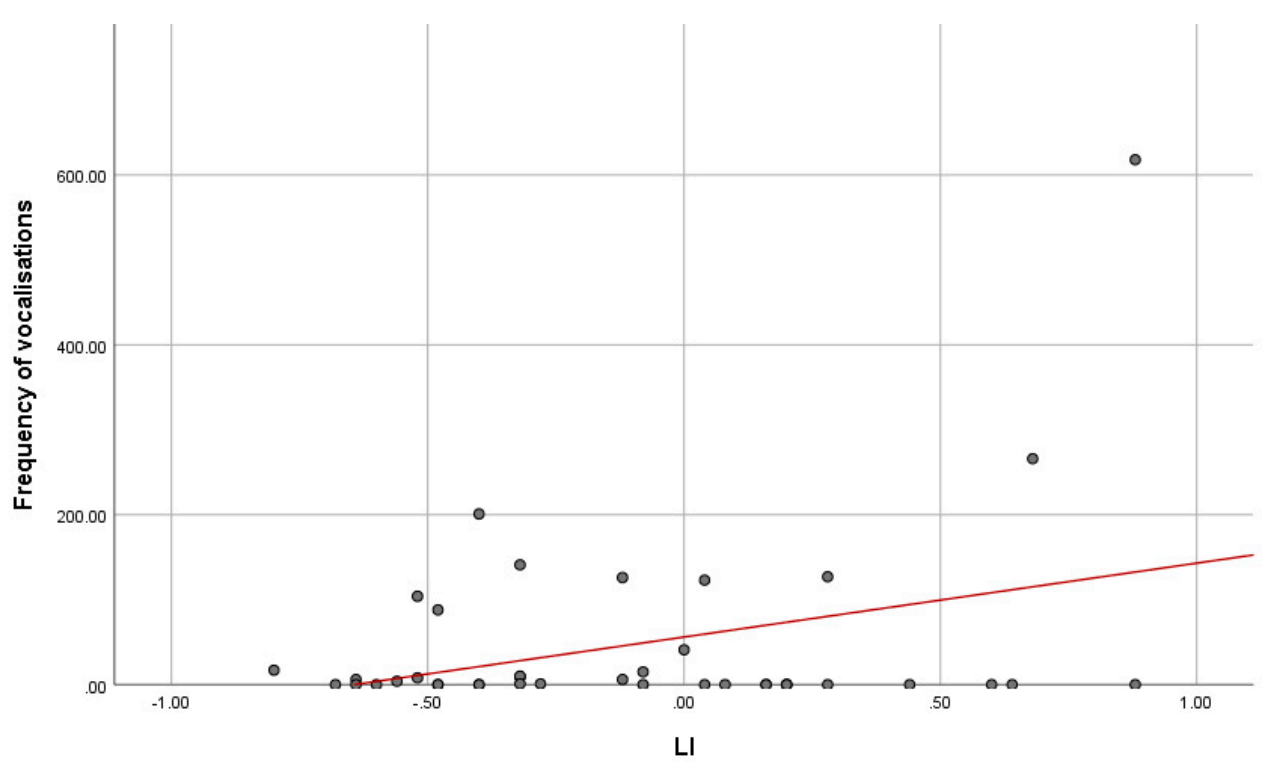

(a)

Figure 1. Cont. 


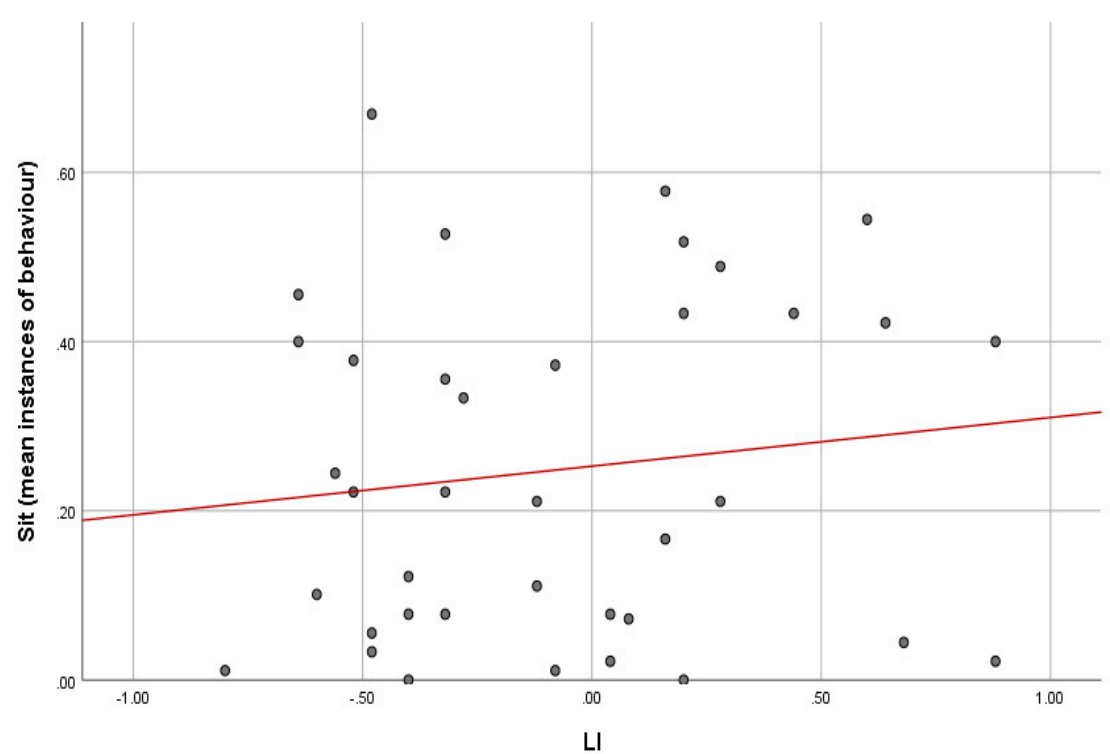

(b)

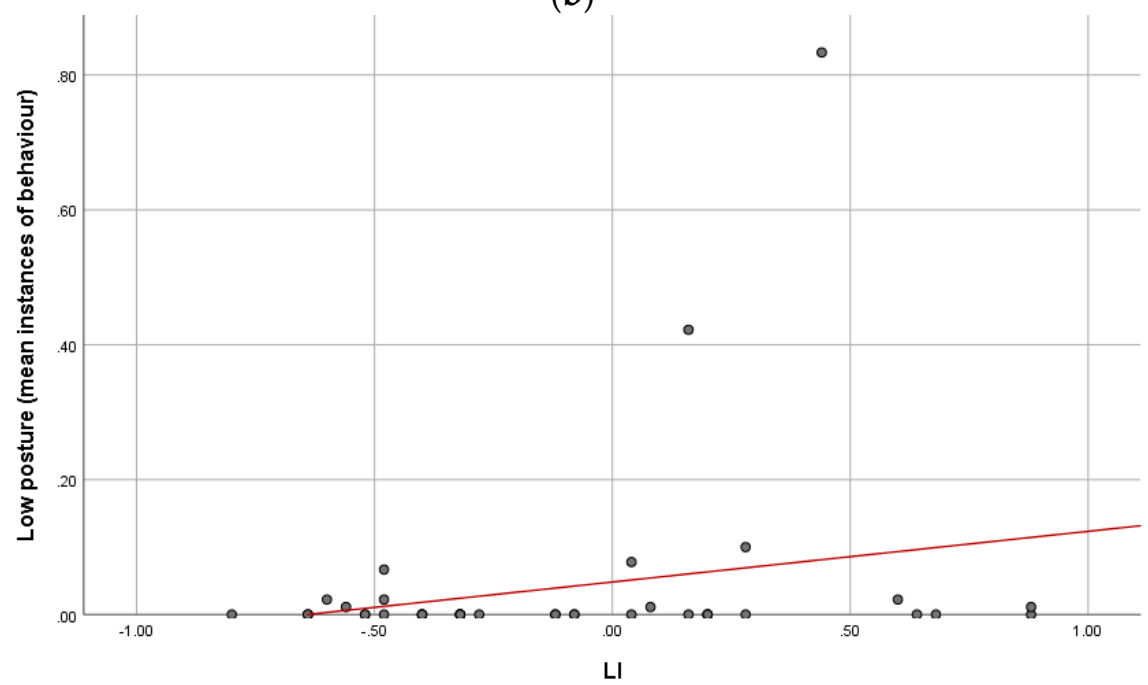

(c)

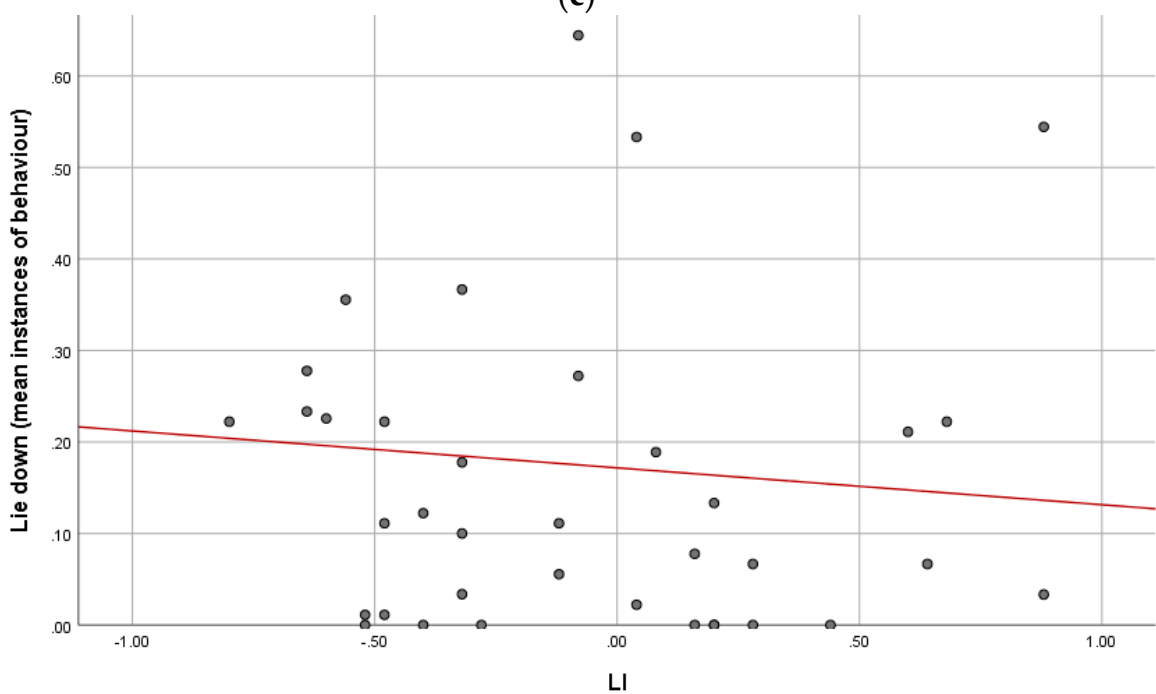

(d)

Figure 1. Regression between laterality index (LI) and vocalising (a), sitting (b), showing a low posture (c), and lying down behaviour (d). LI = -1 strong right-pawed bias; LI = 1 strong left-pawed bias. 
Having a weaker lateralisation was predictive of spending less time lying down, resting/sleeping (Figure 2a) or vocalising (Figure 2b), and more time standing (Figure 2c) and showing a low or high posture.

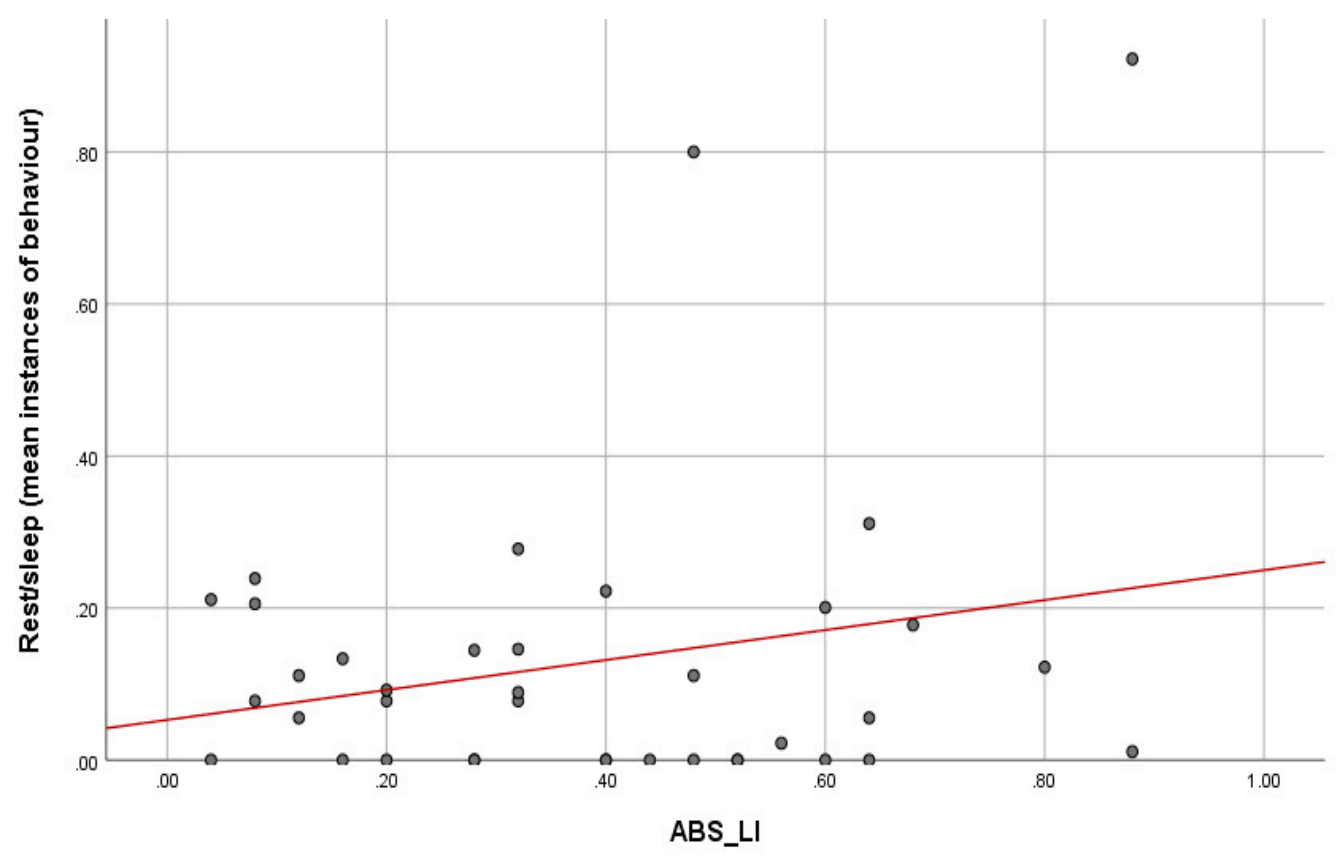

(a)

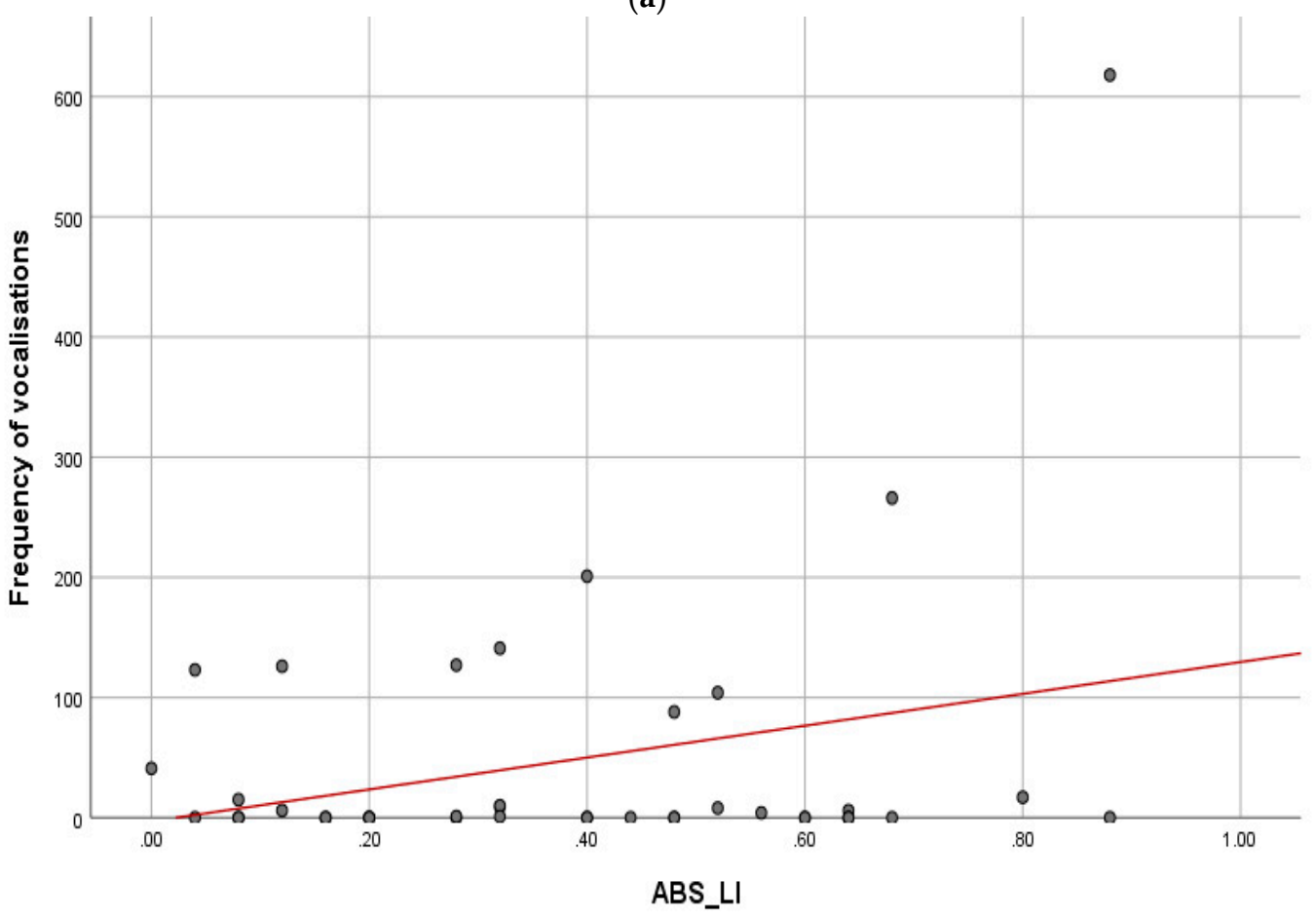

(b)

Figure 2. Cont. 


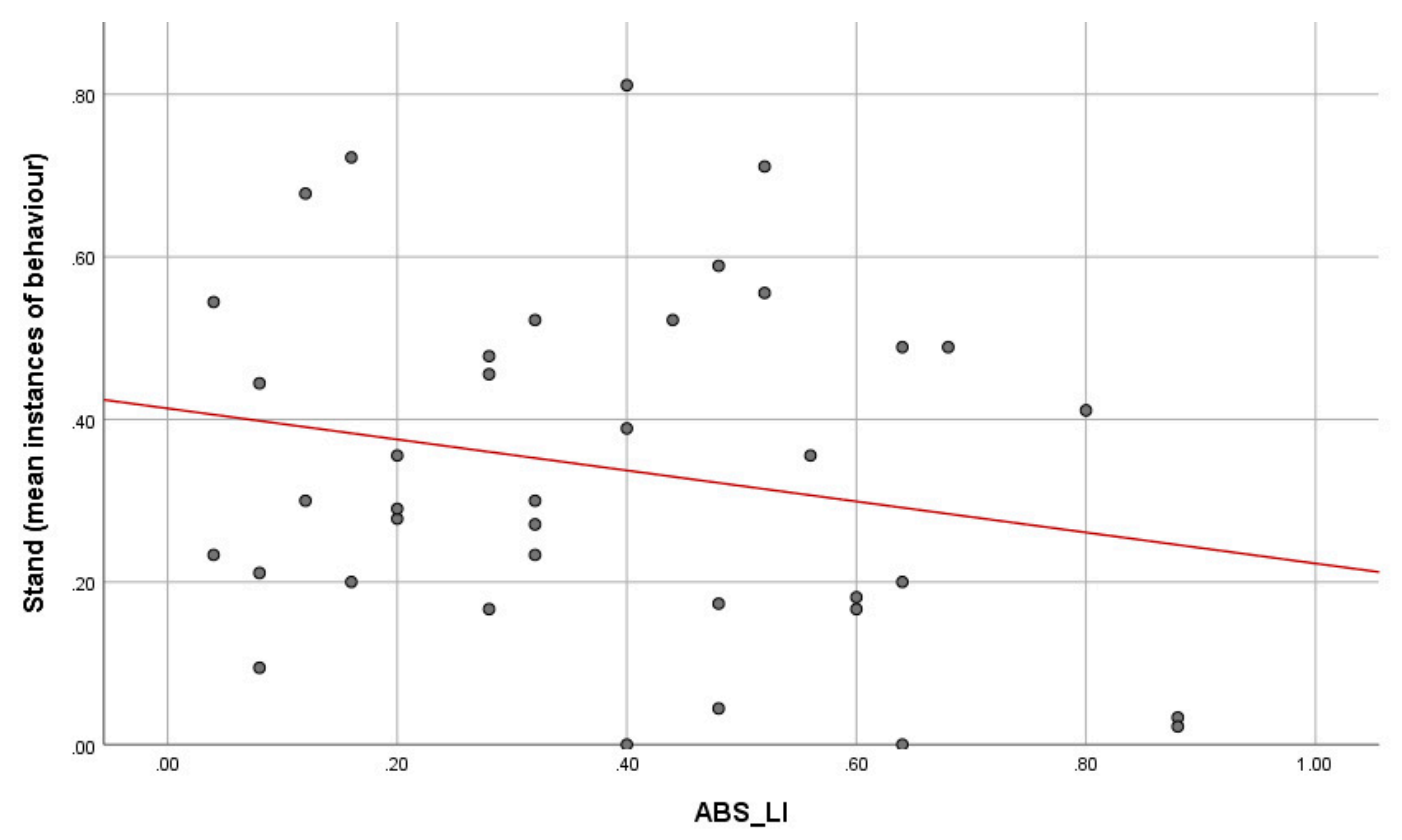

(c)

Figure 2. Association between ABS_LI and rest/sleep (a), vocalization (b) and standing (c). ABS_LI = 0 weak laterality; ABS_LI = 1 strong laterality.

\subsection{Laterality as a Predictive Factor of C/C Level Variation}

LMM showed no significant effect of laterality (direction or strength) on the levels of $\mathrm{C} / \mathrm{C}$ ratio in $\operatorname{dogs}(p>0.05)$.

\section{Discussion}

This study provides the first evidence for the potential use of paw preference as an indicator of coping strategy in dogs entering a kennel environment.

At the individual level, results from the Kong tests revealed a significant paw preference bias (either left or right, 63.4\%), but no significant population bias emerged. This supports some previous research in this area $[23,35,37]$. However, results seem to depend greatly on the population of animals under study, with other authors having reported population biases in dogs $[36,38]$. Neither the direction nor strength of the dogs' paw preferences differed significantly according to canine sex or castration status. Again, the literature is divided on this matter and results appear to be population-dependant [23,32,33,35-37].

Our results showed a relationship between the dogs' paw preferences and certain behaviours. Right-pawedness was associated with a frequent expression of both active and inactive behaviours such as moving or resting/sleeping and lying down. Increasing left-pawedness, by contrast, was associated with a higher expression of stress-related behaviours, including frequent change of state, vocalisations, sitting, and low posture. These results tie in nicely with previous findings of a right hemisphere dominance (left motor bias) in animals being more vulnerable to stress [20]. For example, when stressed by being caged and placed in an unfamiliar environment, cats with higher cortisol levels also had a higher activation of the right brain hemisphere [39].

In a review paper, Rogers [20] suggested that the left hemisphere has a dominant control of proactive/calm behaviours (e.g., approach, exploration) and the right hemisphere of reactive behaviours (e.g., fear, aggression). In marmosets, for example, studies showed that left-handed animals (right hemispheric dominance) were more fearful of alarm calls [40], more likely to show higher cortisol levels [41], and were less reactive to the effects of social facilitation on capturing prey [42] than right-handed marmosets (left hemispheric dominance). Thus, it could be hypothesised 
that animals with a left-limb bias are less likely to exploit new resources and are more likely to express negative emotional functioning compared to individuals with a right-limb bias [32]. Recent studies on marmosets [43] and dogs [44] confirmed this link by observing that a stronger left-limb motor lateralisation was associated with a more negative or 'pessimistic' cognitive bias.

Dogs may show different behavioural styles according to their physiological adaptation. In this study, we found that lower cortisol levels were associated with more frequent observations of moving, standing, and high posture. It could be argued that dogs showing these behaviours were better at coping with the kennel environment, showing a more confident posture and being more active. Hiby and colleagues [13] found that on days when dogs were more active, cortisol levels were lower compared to days when dogs were spending more time sitting or lying down. High activity levels do not necessarily indicate lower stress; there is evidence of increased activity following social and spatial restrictions [7]. It could be the case that staying active helps dogs to cope better with confinement, hence the lower cortisol levels [13]. Interestingly, our results showed that a stronger right-paw bias was linked to higher activity. This lends support for the previously suggested association between left-hemispheric bias and exploratory/proactive coping styles [20].

A high cortisol profile was associated with increased observations of sitting and lying down. Once more these results are in line with findings by Hiby et al. [13]. Both behaviours indicate a more vigilant posture (compared to e.g., resting/sleeping) and a more reactive posture. Following the proactive/reactive hypothesis, dogs showing more sitting and lying behaviour are expected to be more strongly left-pawed. This was only partially true, as we found left-biased dogs did indeed spend more of their time sitting (Figure 1), but less time lying down and resting/sleeping. The link between stress, physiology, and behaviour is complex and still debated [3,5,45]. Multiple factors may play a role in modulating the results, including individual variability and past experiences $[7,13,45]$. Here, we added a new indicator of emotional state (as assessed by motor bias) that could help triangulate our results. If, based on previous work, we consider right-paw biased animals to be less susceptible to environmental stress, we could suggest that animals that either are very active or, on the contrary, very quiet, might cope better overall with novel environmental challenges. Left-pawed dogs, typically reacting to kennelling by showing anxiety and stress-related behaviours such as vocalising, low posture, sitting, and frequently changing state might, on the contrary, find adapting to confinement more challenging.

Strength of laterality (rather than the direction of an animal's motor bias) has been previously associated with increased levels of stress behaviour. In dogs, for example, weaker motor laterality has been linked to higher reactivity and fear of thunderstorms and firework sounds when compared to stronger lateralisation [36]. Our results show that weaker lateralisation was associated with a higher occurrence of standing behaviour and maintenance of a low and high posture. Both high and low posture may be a sign of strong emotional arousal, with different valence (e.g., aggression/extraversion versus fear respectively). Previous work has found that weak limb preference was in fact associated with more fearful, as well as excitable, reactions [31,36]. Having a strongly lateralised brain, by contrast, seems to be advantageous for enhanced cognitive abilities and higher survival fitness [46]. In our study, resting/sleeping and lying down was linked to a higher degree of lateralisation. As mentioned for the right-paw bias, it could be that spending most of the time sleeping helps an individual to cope better with the stress of entering a kennel environment. It is worth mentioning, however, that spending large amounts of time sleeping has also been reported in sheltered dogs as an indicator of learned helplessness and depression-like state [4] and would be more typically associated with a reactive coping style [10].

We found no association between cortisol levels and laterality. The right hemisphere has been found to have a dominant control of endocrine function, especially of the HPA axis [20]. Being associated with more fearful behaviour, left-limb bias should, in theory, be associated with higher corticoid responses than right-limb bias, as found in rhesus macaques and rats $[47,48]$. In dogs, Siniscalchi and collaborators [49] found a chronic elevation of hair cortisol in those individuals 
showing a higher reactivity to acoustic stimuli with different emotional valence. However, Batt and colleagues [31] found no correlation between behaviour, laterality, and salivary cortisol in dogs. This is something that should perhaps be explored further.

Overall, it appears that a left-motor bias may be linked to a more negative affective state, a more reactive coping style, and a more challenging adaptation to novel environments. Assessing paw preference may become a useful tool to detect different coping strategies in dogs entering a kennel and reduce stress in target individuals at higher welfare risk. Further work is needed to explore this in greater depth.

Author Contributions: Conceptualisation: D.L.W. and P.G.H.; Designed experiment: D.L.W. and S.B.; Performed experiment and statistical analysis: S.B.; Wrote the paper: S.B.; Funding acquisition and project supervision: D.L.W. and P.G.H.; All authors revised and approved the paper.

Funding: This research was funded by BBSRC (BB.J021385/1).

Acknowledgments: We are very grateful to Dogs Trust for allowing us access and data collection to be carried out at their Centre in Ballymena, Northern Ireland. Thanks to Richard Turner for developing the smartphone application used in the study. The financial support of the BBSRC (BB.J021385/1) is acknowledged.

Conflicts of Interest: The authors declare no conflict of interest.

\section{References}

1. Stephen, J.M.; Ledger, R.A. A longitudinal evaluation of urinary cortisol in kennelled dogs, Canis familiaris. Physiol. Behav. 2006, 87, 911-916. [CrossRef] [PubMed]

2. Titulaer, M.; Blackwell, E.J.; Mendl, M.; Casey, R.A. Cross sectional study comparing behavioural, cognitive and physiological indicators of welfare between short and long term kennelled domestic dogs. Appl. Anim. Behav. Sci. 2013, 147, 149-158. [CrossRef]

3. Hennessy, M.B. Using hypothalamic-pituitary-adrenal measures for assessing and reducing the stress of dogs in shelters: A review. Appl. Anim. Behav. Sci. 2013, 149, 1-12. [CrossRef]

4. Stephen, J.M.; Ledger, R.A. An audit of behavioral indicators of poor welfare in kenneled dogs in the United Kingdom. J. Appl. Anim. Welf. Sci. 2005, 8, 79-96. [CrossRef] [PubMed]

5. Protopopova, A. Effects of sheltering on physiology, immune function, behavior, and the welfare of dogs. Physiol. Behav. 2016, 159, 95-103. [CrossRef] [PubMed]

6. Beerda, B.; Schilder, M.B.H.; vanHooff, J.; deVries, H.W. Manifestations of chronic and acute stress in dogs. Appl. Anim. Behav. Sci. 1997, 52, 307-319. [CrossRef]

7. Beerda, B.; Schilder, M.B.H.; Van Hooff, J.; De Vries, H.W.; Mol, J.A. Chronic stress in dogs subjected to social and spatial restriction. I. Behavioral responses. Physiol. Behav. 1999, 66, 233-242. [CrossRef]

8. Dalla Villa, P.; Barnard, S.; Di Fede, E.; Podaliri, M.; Di Nardo, A.; Siracusa, C.; Serpell, J.A. Behavioural and physiological responses of shelter dogs to long-term confinement. Vet. Ital. 2013, 49, 231-241. [CrossRef] [PubMed]

9. Hennessy, M.B.; Davis, H.N.; Williams, M.T.; Mellott, C.; Douglas, C.W. Plasma cortisol levels of dogs at a county animal shelter. Physiol. Behav. 1997, 62, 485-490. [CrossRef]

10. Koolhaas, J.M.; Korte, S.M.; De Boer, S.F.; Van Der Vegt, B.J.; Van Reenen, C.G.; Hopster, H.; De Jong, I.C.; Ruis, M.A.W.; Blokhuis, H.J. Coping styles in animals: Current status in behavior and stress-physiology. Neurosci. Biobehav. Rev. 1999, 23, 925-935. [CrossRef]

11. Sloan Wilson, D.; Clark, A.B.; Coleman, K.; Dearstyne, T. Shyness and boldness in humans and other animals. Trends Ecol. Evol. 1994, 9, 442-446. [CrossRef]

12. Horvath, Z.; Igyarto, B.-Z.; Magyar, A.; Miklosi, A. Three different coping styles in police dogs exposed to a short-term challenge. Horm. Behav. 2007, 52, 621-630. [CrossRef] [PubMed]

13. Hiby, E.F.; Rooney, N.J.; Bradshaw, J.W.S. Behavioural and physiological responses of dogs entering re-homing kennels. Physiol. Behav. 2006, 89, 385-391. [CrossRef] [PubMed]

14. Dawkins, M.S. Using behaviour to assess animal welfare. Anim. Welf. 2004, 13, S3-S7.

15. Yeates, J.W.; Main, D.C.J. Assessment of positive welfare: A review. Vet. J. 2008, 175, 293-300. [CrossRef] [PubMed] 
16. Boissy, A.; Lee, C. How assessing relationships between emotions and cognition can improve farm animal welfare. Rev. Sci. Tech. (Int. Off. Epizoot.) 2014, 33, 103-110. [CrossRef]

17. Mendl, M.; Burman, O.H.P.; Parker, R.M.A.; Paul, E.S. Cognitive bias as an indicator of animal emotion and welfare: Emerging evidence and underlying mechanisms. Appl. Anim. Behav. Sci. 2009, 118, 161-181. [CrossRef]

18. Barnard, S.; Matthews, L.; Messori, S.; Podaliri-Vulpiani, M.; Ferri, N. Laterality as an indicator of emotional stress in ewes and lambs during a separation test. Anim. Cogn. 2016, 19, 207-214. [CrossRef] [PubMed]

19. Barnard, S.; Wells, D.L.; Hepper, P.G.; Milligan, A.D.S. Association between lateral bias and personality traits in the domestic dog (Canis familiaris). J. Comp. Psychol. 2017, 131, 246-256. [CrossRef] [PubMed]

20. Rogers, L.J. Relevance of brain and behavioural lateralization to animal welfare. Appl. Anim. Behav. Sci. 2010, 127, 1-11. [CrossRef]

21. Anderson, D.M.; Murray, L.W. Sheep laterality. Laterality 2013, 18, 179-193. [CrossRef] [PubMed]

22. Leliveld, L.M.C.; Langbein, J.; Puppe, B. The emergence of emotional lateralization: Evidence in non-human vertebrates and implications for farm animals. Appl. Anim. Behav. Sci. 2013, 145, 1-14. [CrossRef]

23. Schneider, L.A.; Delfabbro, P.H.; Burns, N.R. Temperament and lateralization in the domestic dog (Canis familiaris). J. Vet. Behav. Clin. Appl. Res. 2013, 8, 124-134. [CrossRef]

24. Davidson, R.J. Cerebral asymmetry, emotion, and affective style. In Brain Asymmetry; Hugdahl, R.J.D.K., Ed.; The MIT Press: Cambridge, MA, USA, 1995; pp. 361-387. ISBN 0-262-04144-8.

25. Rogers, L.J. Evolution of hemispheric specialization: Advantages and disadvantages. Brain Lang. 2000, 73, 236-253. [CrossRef] [PubMed]

26. Andrew, R.J.; Rogers, L.J. The nature of lateralization in tetrapods. In Comparative Vertebrate Lateralization; Cambridge University Press: Cambridge, UK, 2002; pp. 94-125.

27. Rogers, L.J.; Andrew, R. Comparative Vertebrate Lateralization; Cambridge University Press: Cambridge, UK, 2002.

28. Larose, C.; Richard-Yris, M.-A.; Hausberger, M.; Rogers, L.J. Laterality of horses associated with emotionality in novel situations. Laterality 2006, 11, 355-367. [CrossRef] [PubMed]

29. Cameron, R.; Rogers, L.J. Hand preference of the common marmoset (Callithrix jacchus): Problem solving and responses in a novel setting. J. Comp. Psychol. 1999, 113, 149-157. [CrossRef]

30. Reddon, A.R.; Hurd, P.L. Individual differences in cerebral lateralization are associated with shy-bold variation in the convict cichlid. Anim. Behav. 2009, 77, 189-193. [CrossRef]

31. Batt, L.S.; Batt, M.S.; Baguley, J.A.; McGreevy, P.D. The relationships between motor lateralization, salivary cortisol concentrations and behavior in dogs. J. Vet. Behav. Clin. Appl. Res. 2009, 4, 216-222. [CrossRef]

32. Siniscalchi, M.; d'Ingeo, S.; Quaranta, A. Lateralized functions in the dog brain. Symmetry 2017, 9, 71. [CrossRef]

33. Wells, D.L. Lateralised behaviour in the domestic dog, Canis familiaris. Behav. Process. 2003, 61, 27-35. [CrossRef]

34. Tomkins, L.M.; Williams, K.A.; Thomson, P.C.; McGreevy, P.D. Lateralization in the domestic dog (Canis familiaris): Relationships between structural, motor, and sensory laterality. J. Vet. Behav. Clin. Appl. Res. 2012, 7, 70-79. [CrossRef]

35. Marshall-Pescini, S.; Barnard, S.; Branson, N.J.; Valsecchi, P. The effect of preferential paw usage on dogs' (Canis familiaris) performance in a manipulative problem-solving task. Behav. Process. 2013, 100, 40-43. [CrossRef] [PubMed]

36. Branson, N.J.; Rogers, L.J. Relationship between paw preference strength and noise phobia in Canis familiaris. J. Comp. Psychol. 2006, 120, 176-183. [CrossRef] [PubMed]

37. Poyser, F.; Caldwell, C.; Cobb, M. Dog paw preference shows lability and sex differences. Behav. Process. 2006, 73, 216-221. [CrossRef] [PubMed]

38. Siniscalchi, M.; Quaranta, A.; Rogers, L.J. Hemispheric specialization in dogs for processing different acoustic stimuli. PLoS ONE 2008, 3, e3349. [CrossRef] [PubMed]

39. Mazzotti, G.A.; Boere, V. The right ear but not the left ear temperature is related to stress-induced cortisolaemia in the domestic cat (Felis catus). Laterality Asymmetries Body Brain Cogn. 2009, 14, 196-204. [CrossRef] [PubMed]

40. Braccini, S.N.; Caine, N.G. Hand preference predicts reactions to novel foods and predators in marmosets (Callithrix geoffroyi). J. Comp. Psychol. 2009, 123, 18-25. [CrossRef] [PubMed] 
41. Rogers, L.J. Hand and paw preferences in relation to the lateralized brain. Philos. Trans. R. Soc. Lond. B Biol. Sci. 2009, 364, 943-954. [CrossRef] [PubMed]

42. Gordon, D.J.; Rogers, L.J. Differences in social and vocal behavior between left- and right-handed common marmosets (Callithrix jacchus). J. Comp. Psychol. 2010, 124, 402-411. [CrossRef] [PubMed]

43. Gordon, D.J.; Rogers, L.J. Cognitive bias, hand preference and welfare of common marmosets. Behav. Brain Res. 2015, 287, 100-108. [CrossRef] [PubMed]

44. Wells, D.L.; Hepper, P.G.; Milligan, A.D.S.; Barnard, S. Cognitive bias and paw preference in the domestic dog (Canis familiaris). J. Comp. Psychol. 2017, 131, 317-325. [CrossRef] [PubMed]

45. Rooney, N.J.; Gaines, S.A.; Bradshaw, J.W.S. Behavioural and glucocorticoid responses of dogs (Canis familiaris) to kennelling: Investigating mitigation of stress by prior habituation. Physiol. Behav. 2007, 92, 847-854. [CrossRef] [PubMed]

46. Rogers, L.J. A matter of degree: Strength of brain asymmetry and behaviour. Symmetry 2017, 9, 57. [CrossRef]

47. Westergaard, G.C.; Chavanne, T.J.; Lussier, I.D.; Houser, L.; Cleveland, A.; Suomi, S.J.; Higley, J.D. Left-handedness is Correlated with CSF Monoamine Metabolite and Plasma Cortisol Concentrations, and with Impaired Sociality, in Free-ranging Adult Male Rhesus Macaques (Macaca mulatta). Laterality Asymmetries Body Brain Cogn. 2003, 8, 169-187. [CrossRef] [PubMed]

48. Neveu, P.J.; Moya, S. In the mouse, the corticoid stress response depends on lateralization. Brain Res. 1997, 749, 344-346. [CrossRef]

49. Siniscalchi, M.; McFarlane, J.R.; Kauter, K.G.; Quaranta, A.; Rogers, L.J. Cortisol levels in hair reflect behavioural reactivity of dogs to acoustic stimuli. Res. Vet. Sci. 2013, 94, 49-54. [CrossRef] [PubMed]

(C) 2018 by the authors. Licensee MDPI, Basel, Switzerland. This article is an open access article distributed under the terms and conditions of the Creative Commons Attribution (CC BY) license (http:/ / creativecommons.org/licenses/by/4.0/). 